\title{
Design and Implementation of Induction Coil for Case Hardening of a Carbon Steel Gear
}

\author{
Hamdan F. Sabeeh', Isam M. Abdulbaqi'1, and Sahib M. Mahdi2 \\ ${ }^{1}$ Electrical Engineering Department, Al-Mustansiriyah University, Baghdad, Iraq \\ ${ }^{2}$ Material Engineering Department, Al-Mustansiriyah University, Baghdad, Iraq \\ Corresponding author: Hamdan F. Sabeeh (hamdan.alramahe@yahoo.com).
}

\begin{abstract}
This work includes a design of an induction coil as a guide to design an induction furnace as a part of a production line suitable for achieving case hardening of a CK-45 carbon steel gear in a mass production factory. Such a workpiece requires certain hardening profile in that the periphery including the gear teeth must be hardened for certain depth to withstand against corrosion, while the rest volume must be of low hardness in order to overcome mechanical stresses due to the coupled shaft. Induction heating technology adopted for achieving such a complex hardness profile in one workpiece. A numerical simulation intended to design the induction coil, then the induction furnace able to perform this hardening requirement. A three dimensional (3-D) electromagnetic-thermal coupled analysis using Finite Element Method (FEM) is intended to design this coil. This design must determine the required frequency, current, and temperature required for this process at certain required time. These parameters are the guide to build the suitable induction furnace power supply for this task. This work proves the truth that this simulation is quite accurate to implement a pioneer system.
\end{abstract}

INDEX TERMS Coil parameters, FEM, Induction heating, Surface hardening.

\section{INTRODUCTION}

T HE case or surface hardening of a carbon steel gear is one of the most interested processes in industry, so, this work deals with its details. Certain heat treatment is intended to make the inner parts of the gear able to withstand against high stresses to avoid fracture and protect its external teeth surface from wear simultaneously [1].

The induction heating is one of the preferred methods to perform this task. The workpiece (specimen) to be hardened shown in Fig. 1 is a gear made of carbon steel CK-45. This process is a function of many parameters like workpiece geometry, workpiece material alloy, the required depth of hardening ... etc. Fig. 2 represents the interrelation between these different parameters. Due to the complexity of this process, the FEM intended to simulate this process to determine the induction coil parameters suitable to heat the required part of the workpiece to the required hardening temperature at the required time. If these parameters are determined then the power, the frequency, and the output voltage of the required power source feeding the induction coil can be prepared.

In such process if the design of the induction heating system depends on the experts, then it will be costly, tedious and require a long time to reach the suitable design. Hence, the electromagnetic-thermal coupled analysis intended for this purpose. This work includes the requirements of the case hardening from the Metallurgy point of view, since this process depends on the (steel phase equilibrium diagram) and on the (time-temperature cooling diagram) to determine both the required temperature and the quenching time of the hardening process depending on the carbon content of the steel alloy [2].

The implementation of a prototype of such induction heating system intended to prove the simulation results accuracy. hence, real test done on the workpiece using the implemented prototype, to approve the specified temperature and time. Also, a hardness test is done on the processed workpiece to insure its hardness. The results achieved approve the accuracy of the simulation process.

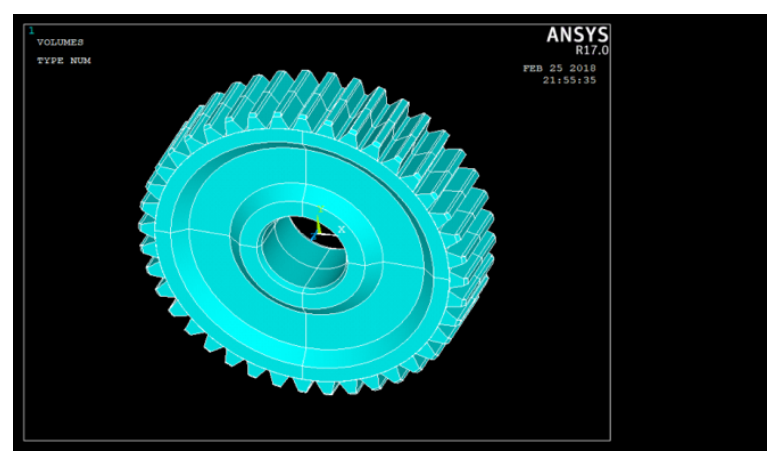

FIGURE 1. The gear under study 


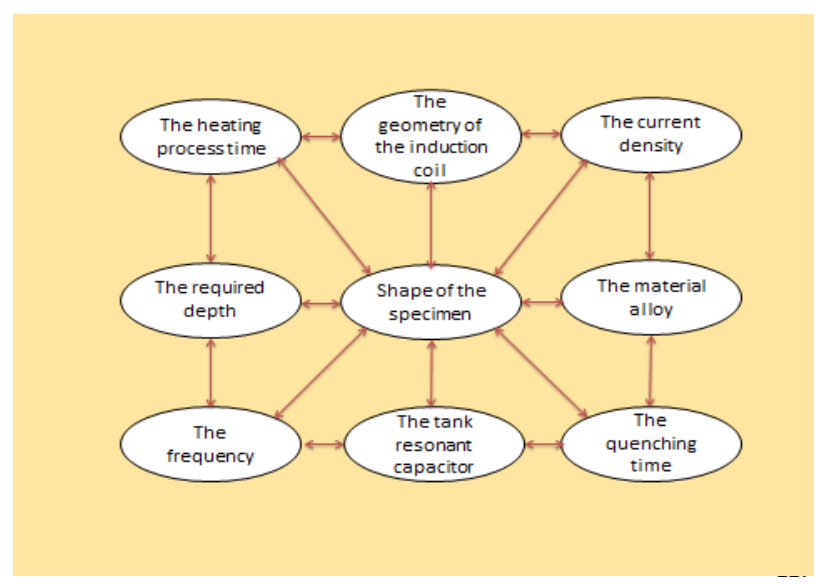

FIGURE 2. The complexity of the induction heating process

\section{THEORETICAL BACKGROUND}

The electromagnetic field analysis uses the differential form of the Quasi-static Maxwell's equations for general timevarying electromagnetic fields to determine the induced eddy currents and the power per unit volume in the specimen as follows [4]:

Ampere's circuital law:

$$
\nabla \times \overrightarrow{\mathrm{H}}=\overrightarrow{\mathrm{J}}
$$

Faraday's law of induction:

$$
\nabla \times \overrightarrow{\mathrm{E}}=-\frac{\partial \overrightarrow{\mathrm{B}}}{\partial \mathrm{t}}
$$

Gauss's law for magnetism:

$$
\nabla \cdot \overrightarrow{\mathrm{B}}=0
$$

Gauss's law:

$$
\nabla \cdot \overrightarrow{\mathrm{D}}=\rho
$$

Where $\overrightarrow{\mathrm{H}}$ is the magnetic field intensity, $\overrightarrow{\mathrm{J}}$ is conduction current density, $\vec{D}$ is an electric flux density, $\vec{E}$ is the electric field intensity, $\vec{B}$ is the magnetic flux density, $\rho$ is the electric charge density.

For the induction in the specimen, the above equations lead to that the power per unit volume:

$$
\mathrm{Q}_{\text {induction }}=\frac{\left|\mathrm{J}_{\text {eddy }}\right|^{2}}{\sigma_{\text {core }}}
$$

This steady state analysis results are followed by a transient thermal analysis (for a specified time step) in order to determine the heat distribution inside the workpiece during that time. The Fourier equation describes the transient heat transfer process in metal [5]:

$$
\rho_{\mathrm{m}} \mathrm{C}_{\mathrm{p}} \frac{\partial \mathrm{T}}{\partial \mathrm{t}}=\mathrm{k} \nabla^{2} \mathrm{~T}+\mathrm{Q}_{\text {induction }}
$$

Where, $\rho_{m}$ is the metal density, $C_{p}$ is its specific heat, $T$ is the temperature, $\mathrm{k}$ is the metal thermal conductivity and
$\mathrm{Q}_{\text {induction }}$ is the induced density of the heat source in induction heating due to the induced eddy currents per unit time and per unit volume.

The main equation in the heat transfer process in induction heating applications which represent the boundary condition on the surface of the workpiece is:

$$
\begin{aligned}
\rho_{\mathrm{m}} \mathrm{C}_{\mathrm{p}} \frac{\partial \mathrm{T}}{\partial \mathrm{t}}=\mathrm{k} \nabla^{2} \mathrm{~T} & +\mathrm{Q}_{\text {induction }}-\xi \sigma_{\mathrm{s}}\left(\mathrm{T}^{4}-\mathrm{T}_{\mathrm{air}}{ }^{4}\right) \\
& -\alpha\left(\mathrm{T}-\mathrm{T}_{\text {air }}\right) \cdots \cdots \cdots \cdots \cdots \cdots(7)
\end{aligned}
$$

Where: $\xi$ the surface emissivity, and $\sigma_{\mathrm{s}}$ is Stefan-Boltzmann constant.

\section{THE REQUIRED PROCESS}

It is too important to declare that such a research deals with a surface hardening problem that must be done under restrictions in quality achieved and time elapsed to harden each piece. Hence, the design must prove these requirements before starting to build the hardware of the induction furnace, unless the task cannot be fulfilled.

The specimen (the gear) shown in Fig.1 is of a complicated shape and each part has its definition in gear terminology. Fig. 3 (a) and Fig. 3 (b), [5], show the general gear terminology used by mechanical engineers.
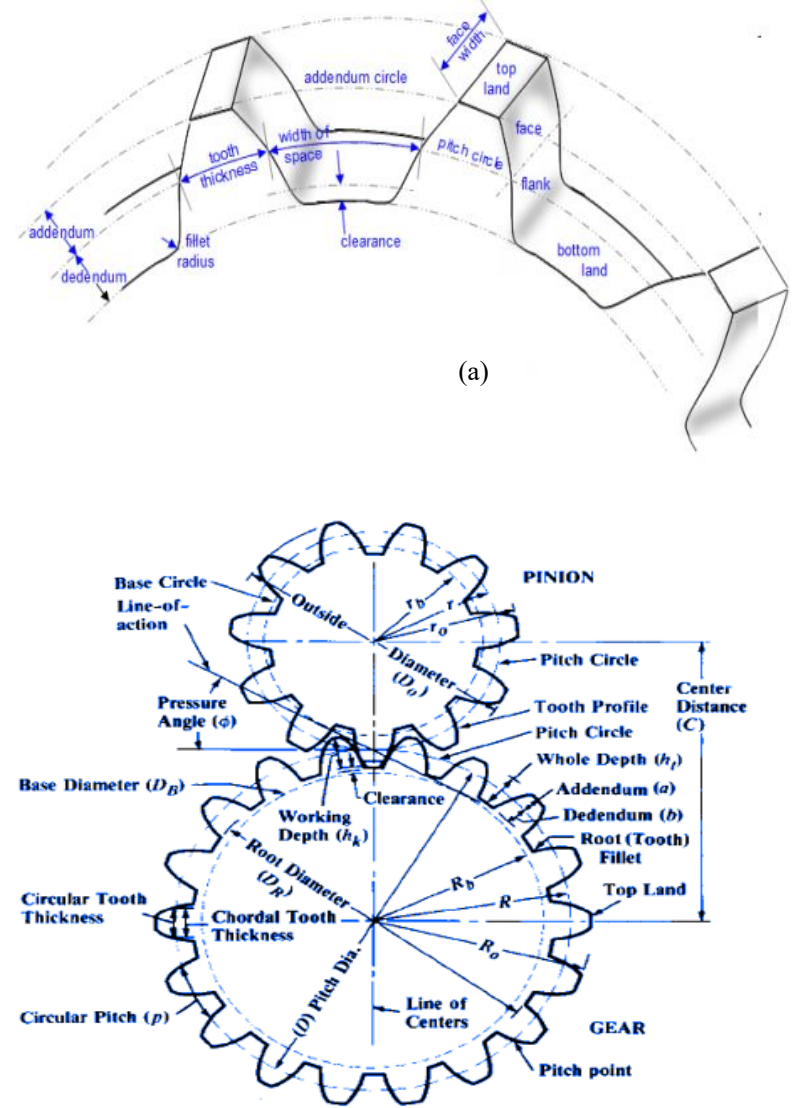

(b) 
Table I. Gear data

\begin{tabular}{lcc}
\hline \hline \multicolumn{1}{c}{ Symbol } & Unit & Value \\
\hline Addendum $(a)$ & $\mathrm{mm}$ & 2.75 \\
Dedendum $(b)$ & $\mathrm{mm}$ & 2.75 \\
Root diameter $\left(D_{R}\right)$ & $\mathrm{mm}$ & 94 \\
Total gear diameter $\left(D_{o}\right)$ & $\mathrm{mm}$ & 105 \\
Number of teeth & $\mathrm{No}$. & 40 \\
Total depth $\left(h_{t}\right)$ & $\mathrm{mm}$ & 5.5 \\
Tooth face width & $\mathrm{mm}$ & 28.5
\end{tabular}

Table II. Chemical composition of CK-45

\begin{tabular}{ccc}
\hline \hline Element & Unit & Value \\
\hline $\mathrm{C}$ & $\%$ & 0.483 \\
$\mathrm{Si}$ & $\%$ & 0.284 \\
$\mathrm{Mn}$ & $\%$ & 0.706 \\
$P$ & $\%$ & 0.0145 \\
$\mathrm{~S}$ & $\%$ & 0.021 \\
$\mathrm{Cr}$ & $\%$ & 0.0524 \\
$\mathrm{Mo}$ & $\%$ & $<0.002$ \\
$\mathrm{Ni}$ & $\%$ & 0.0206 \\
$\mathrm{Al}$ & $\%$ & 0.0507 \\
$\mathrm{Cu}$ & $\%$ & 0.0255 \\
$\mathrm{~W}$ & $\%$ & 0.033 \\
$\mathrm{Fe}$ & $\%$ & Remaining \\
\hline \hline
\end{tabular}

Fig. 4 represents the front view of the gear under study, while the shaded area of $8.8 \mathrm{~mm}$ width is the region to be hardened which must be 1.6 times the length of the tooth of $5.5 \mathrm{~mm}$.

Due to Engineering Metallurgy Science, the surface hardening or case hardening of carbon steel is defined as the change in its phase (crystal lattice) from the Body-Centered Cubic (BCC) in $25^{\circ} \mathrm{C}$ to another phase known as (Martensite) or the Body-Centered Tetragonal (BCT) in $25^{\circ} \mathrm{C}[6]$.

This transformation from (BCC) or ( $\alpha$-Iron) to (BCT) or (Martensite) is not happened directly, but it occurs due to the raise in temperature of the (BCC) to certain degree defined by the steel phase equilibrium diagram to another phase known as Face-Centered Cube (FCC) or (Austenite) at that temperature, then it is cooled rapidly to reach the $(\mathrm{BCT})$. The crystal lattice of these three phases is shown in Fig. 5.

In order to use the steel phase equilibrium diagram mentioned above, the chemical composition of the steel must be known to determine the carbon content. This value determines the required temperature for the steel to transfer from (BCC) to (FCC) crystal lattice as shown in Fig. 6.

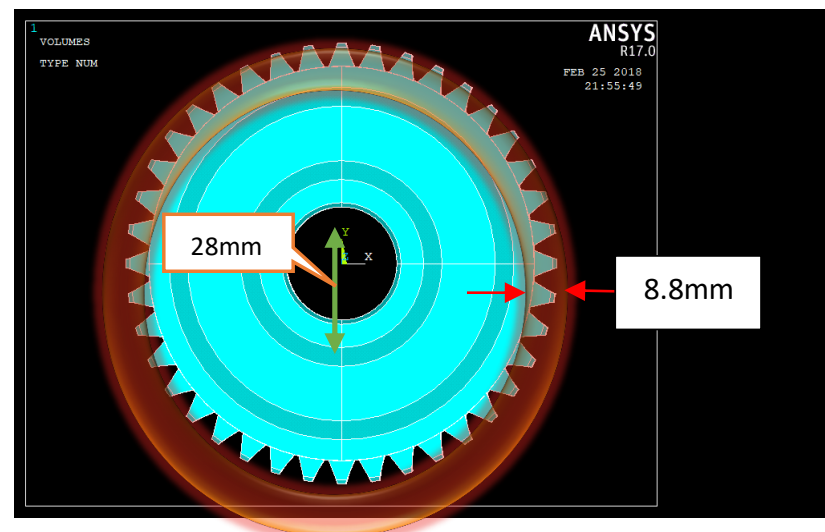

FIGURE 4. Gear front view, show shaft hall and the region to be hardened.
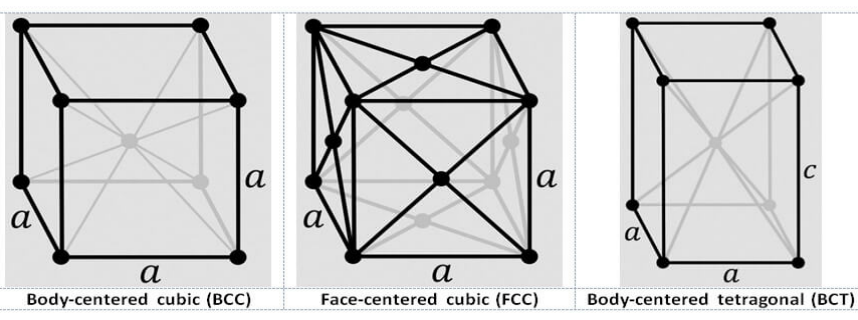

$\alpha-$ Iron at $25^{\circ} \mathrm{C}$

Austenite at $800^{\circ} \mathrm{C}$

Martensite at $25^{\circ} \mathrm{C}$

FIGURE 5. Phases transformation of carbon steel during the hardening process

Table II show the chemical content of the steel alloy. Then due to the carbon content of $0.483 \%$, the steel phase equilibrium diagram show that the required heating temperature is $\left(800\right.$ to $\left.830^{\circ} \mathrm{C}\right)$. The rate of the cooling (quenching) step is determined by the (Time-temperature cooling diagram) shown in Fig. 7. The blue line declares that the temperature of $200^{\circ} \mathrm{C}$ must be dissipated during 10 seconds to reach the $(\mathrm{BCT})$ cells of the surface hardening.

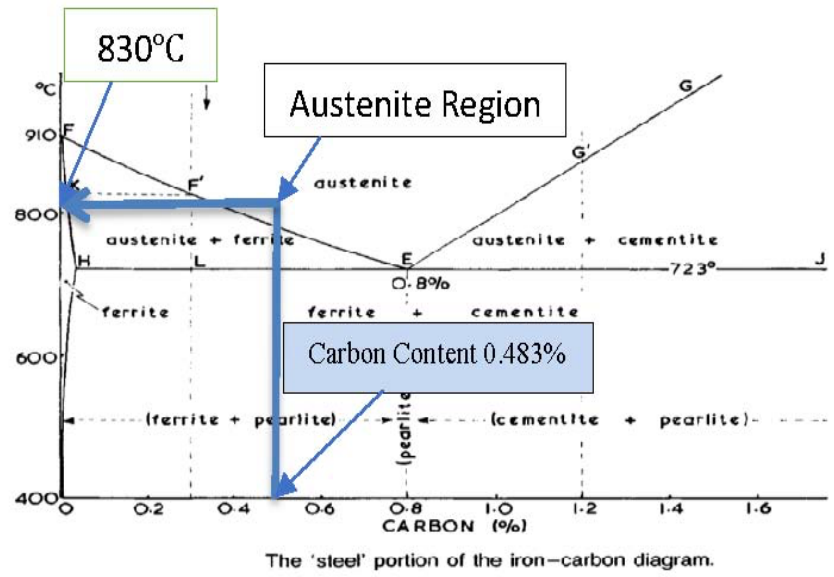

FIGURE 6. Steel phase equilibrium diagram 


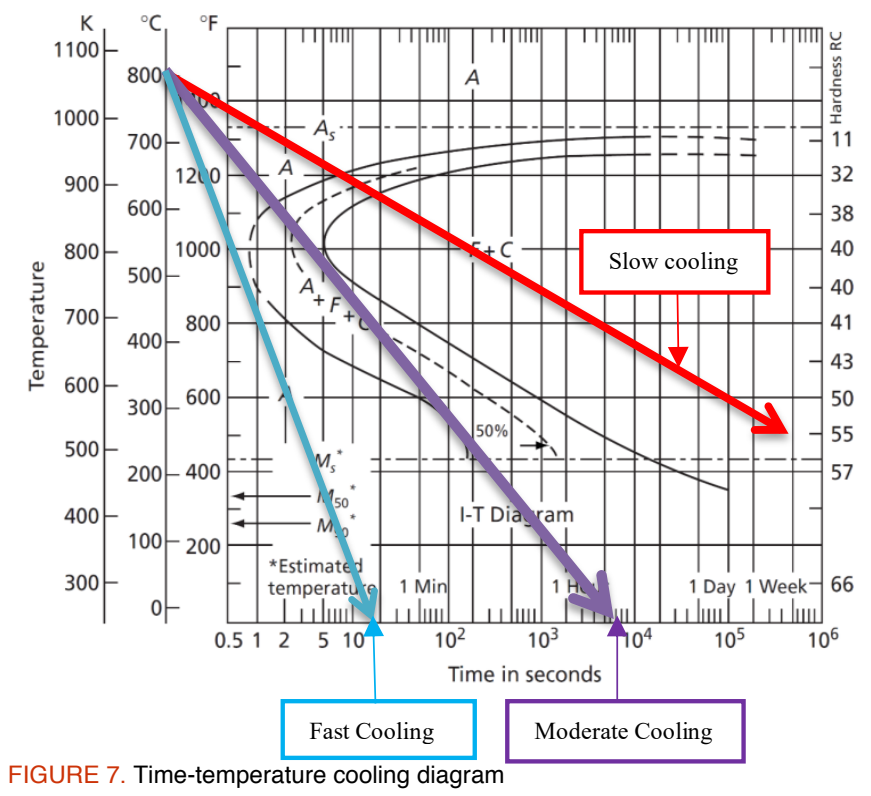

Such a complex heat treatment must be simulated due to the electromagnetic-thermal coupled analysis. This numerical analysis is very advantageous to reduce the time, design efforts and cost of the design.

\section{INDUCTION COIL DESIGN}

Normally, the shape of the induction coil follows the shape of the specimen, so the expected shape of the induction coil is a hollow cylindrical shape around the specimen periphery. Also, the coil conductor must be a copper pipe to allow the cooling water flow in it. The thickness of the conductor wall must be sufficient to pass the coil current at its frequency (of low resistance). Hence, the skin effect must be considered in choosing this parameter. The available conductor for this mission is a hollow copper cylindrical tube of wall thickness of $1 \mathrm{~mm}$ and an external radius of $4.75 \mathrm{~mm}$. This tube must be isolated by a thermal and electrical insulator, hence about $1 \mathrm{~mm}$ of distance separating the coil turns. The primary shape of the coil with the specimen is that shown in Fig. 8 [7-8].

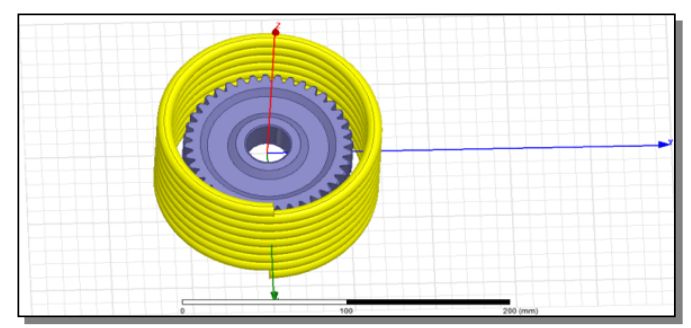

FIGURE 8. The ordinary induction coil for hardening

To study this preliminary design, the electromagnetic-thermal coupled analysis using finite element method to solve Maxwell's equations and the thermal equations numerically by using ANSYS software package. The electromagnetic analysis is a steady-state (harmonic) analysis responsible to determine the flux distribution on the specimen and the induced eddy currents in it, while the thermal transient analysis follow it to determine the temperature distribution inside the specimen. Fig. 9 shows the flow chart of this process [9-12].

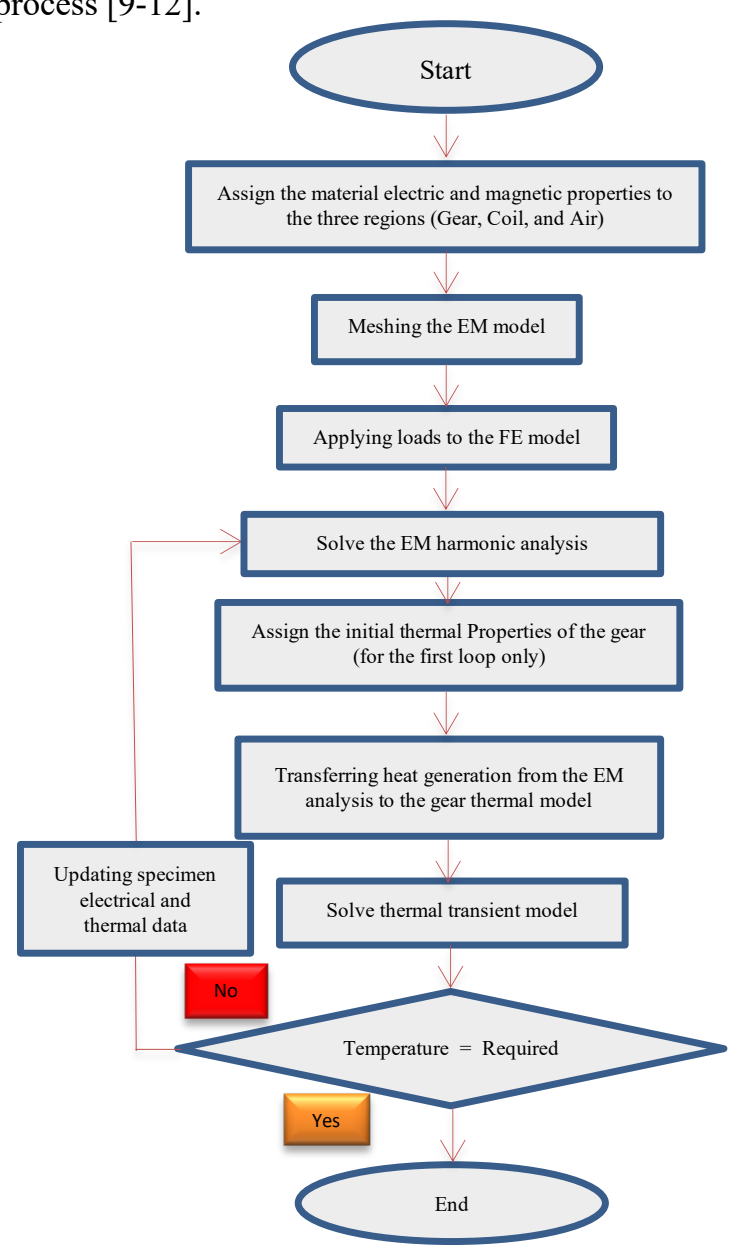

FIGURE 9. The flowchart diagram of the electromagnetic-thermal coupled analysis describing the induction heating process

The 3-D FE model of the gear under study is shown in Fig. 10. This figure shows the huge number of elements which is require an unreasonable processing time.

In order to reduce this time of such a tedious analysis the $18^{\circ}$ section of the 3-D model considered in this analysis as that shown in Fig. 11 due to symmetry.

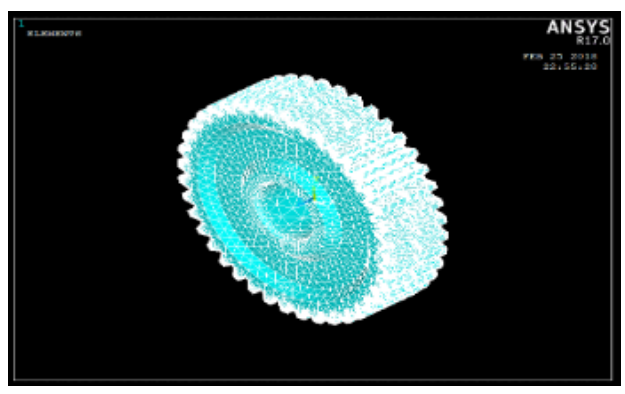

FIGURE 10. FE model of the gear under study 


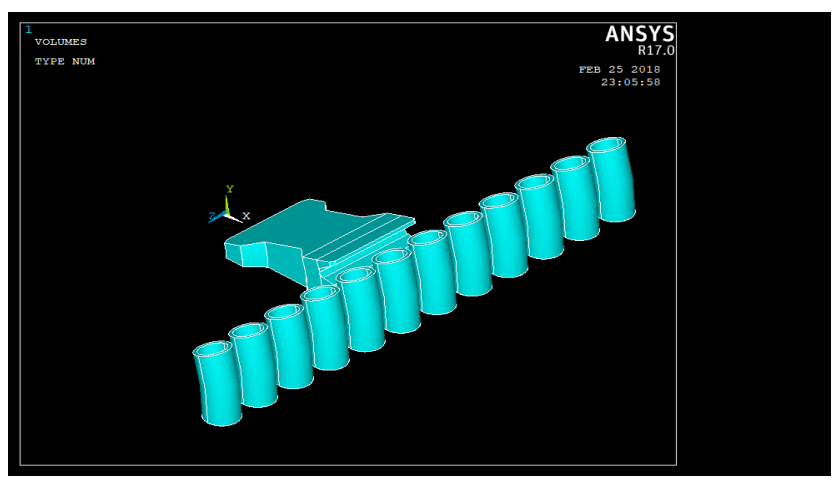

FIGURE 11. The $18^{\circ}$ section of the gear and the induction coil

These analyses lead to study the effect of variations in coil parameters on the performance of the process. It studies the effect of coil diameter, coil number of turns, coil pitch (the distance between coil turns), the magnitude of the coil current and its frequency on the maximum temperature at the gear edge for specific time of the process.

Due to the electromagnetic analysis only, Fig. 12 and Fig. 13 show the effect of the variation in induction coil radius on the maximum flux density on the specimen, for different number of turns (3, 6, 9, and 12) and for different coil pitches consequently.

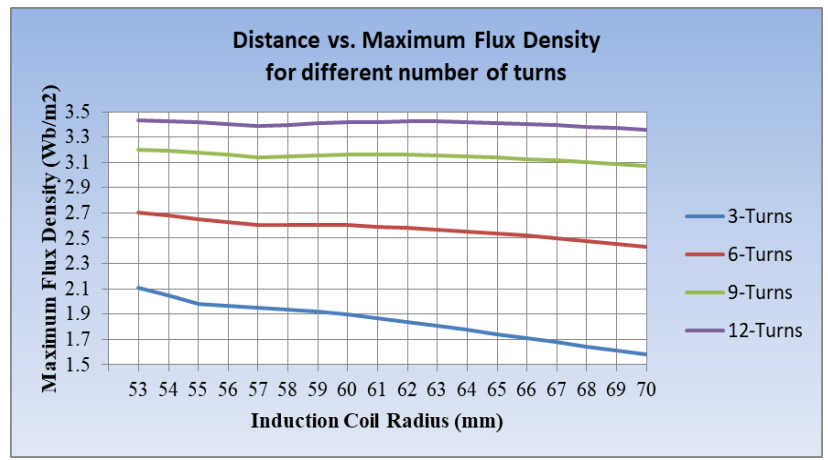

FIGURE 12. Change of maximum flux density for the node at the edge of the gear against different number of turns

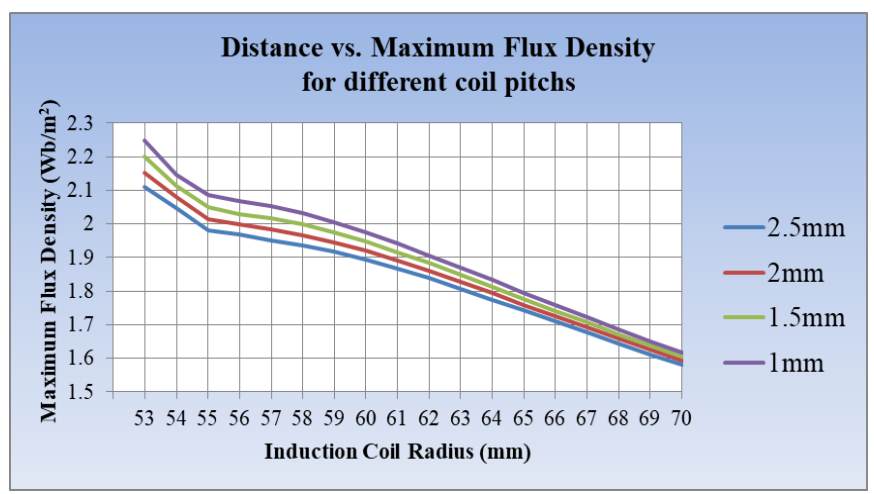

FIGURE 13. Change of maximum flux density for the node at the edge of the gear for different coil pitches

\section{3-Turns}

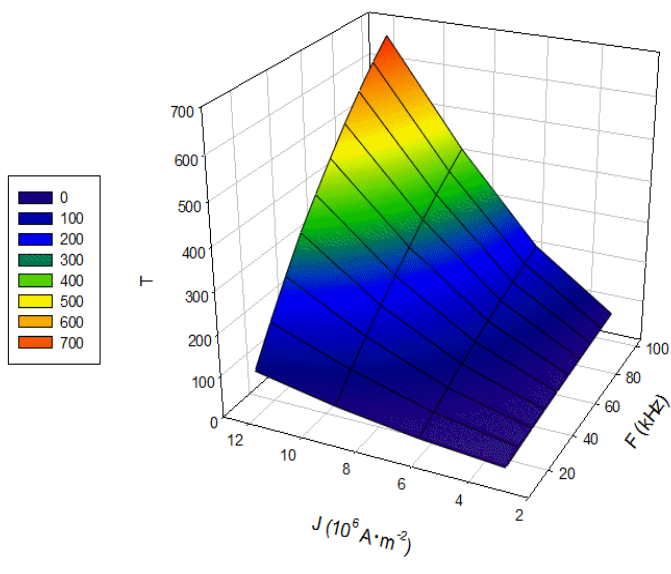

6-Turns

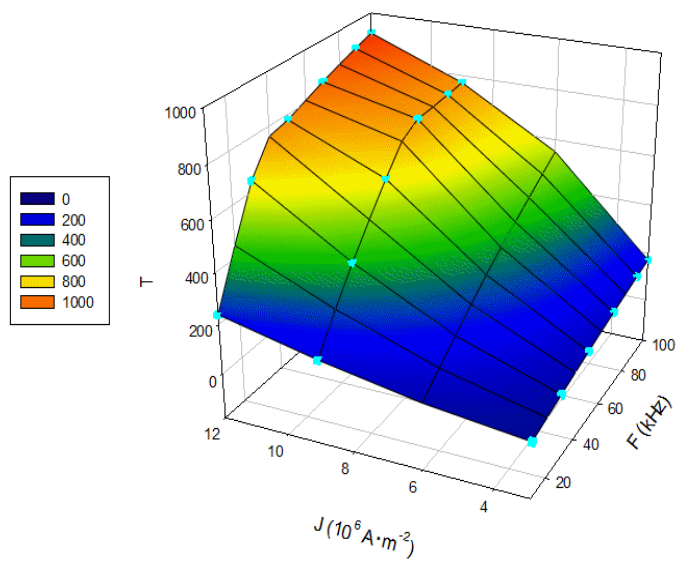

FIGURE 14. The relation between current density, frequency variation on the maximum temperature of the specimen for 3 and 6 turns

While due to the electromagnetic-thermal coupled analyses, Fig. 14 and Fig. 15 shows the effect of variation in number of turns, coil current density, and frequency on the maximum temperature appears on gear edge.

The obtained results reveal that the 12 turns will lead to the highest temperature due to the flux concentration on the gear, and the frequency range over $70 \mathrm{kHz}$ is the most effective, while the increase in frequency must be avoided in order to concentrate the flux on the required depth of the gear periphery. Also, the current density effective range is that greater than $\left(8 \mathrm{MA} / \mathrm{m}^{2}\right)$. The criteria of reaching the best choice among these variables, is to obtain the required temperature at the required depth in a reasonable processing time for each workpiece. The most effective choice that perform the acceptable temperature profile during $245 \mathrm{~s}$ is achieved when a 12turns coil of $115 \mathrm{~mm}$ in radius and of coil pitch of $1 \mathrm{~mm}$ fed by a $75 \mathrm{kHz}$, current density of $9 \mathrm{MA} / \mathrm{m}^{2}$, as 
shown in Fig. 16. This temperature distribution assures the required temperature in the required region to be hardened.
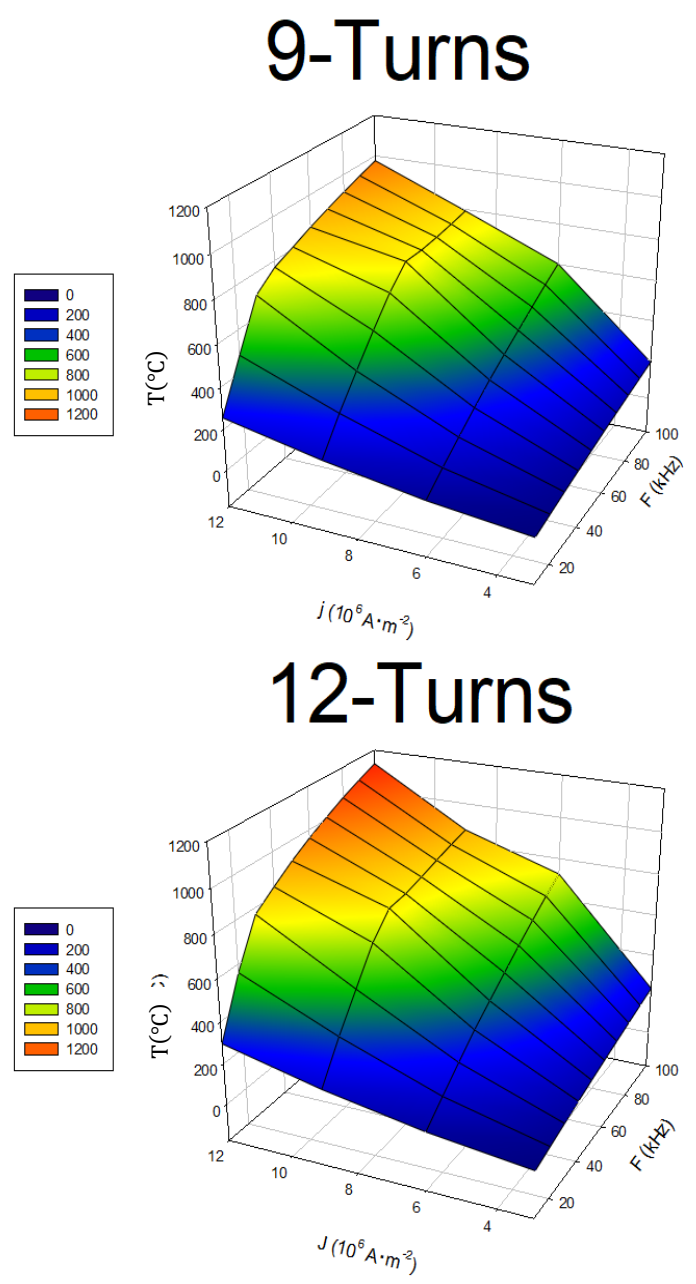

FIGURE 15. The relation between current density, frequency variation on the maximum temperature of the specimen for 9 and 12 turns

To explain the heating process, 5 nodes were chosen on the gear section as shown in Fig. 17. The temperature vs time for each of these nodes shown in Fig. 18.

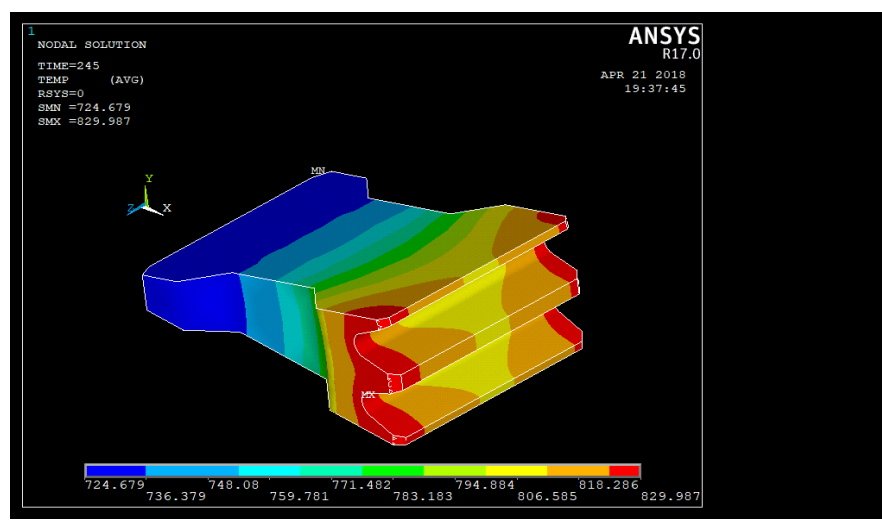

FIGURE 16. The temperature distribution on the gear at 245 s of the process.

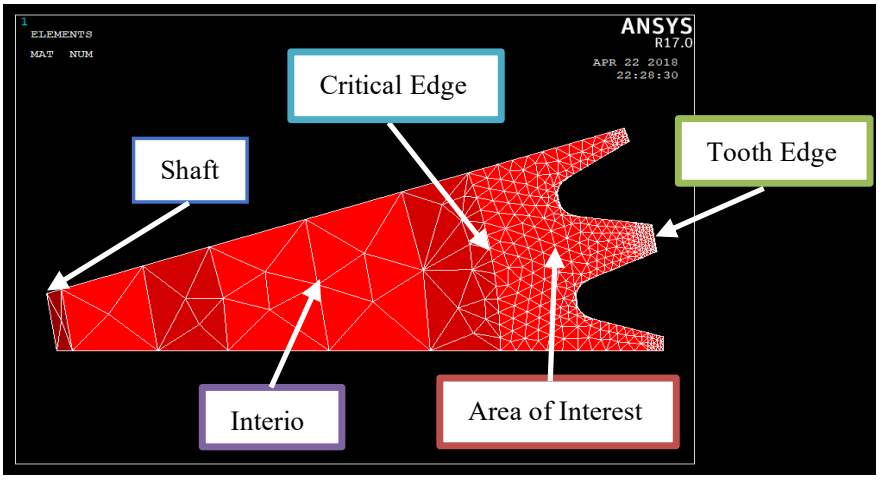

FIGURE 17. The location of the selected nodes on the gear surface.

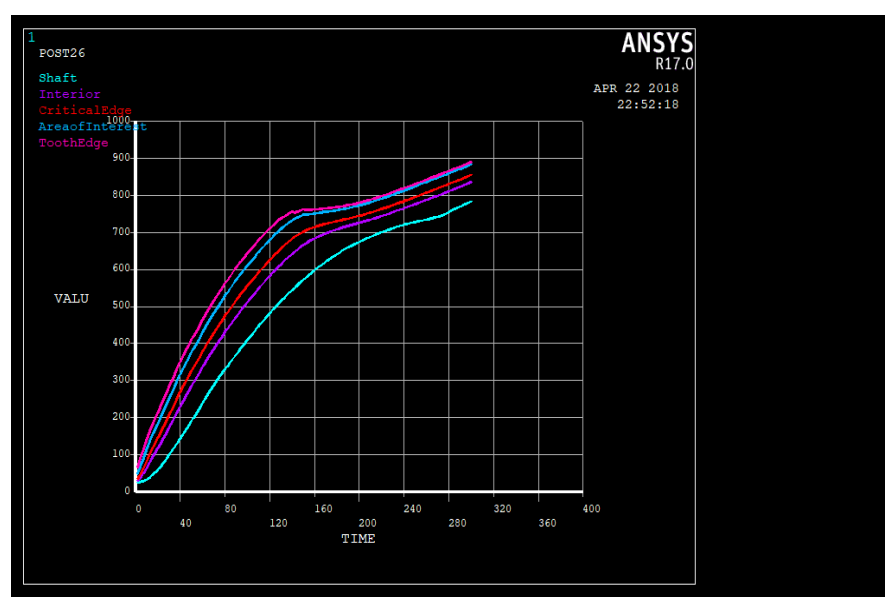

FIGUR 18. The temperature profile of the 5 nodes during the process of $254 \mathrm{~s}$.

The obtained results assign the change in behavior of the temperature-time curve over $750^{\circ} \mathrm{C}$. This degree is known as Curie Temperature. At this temperature the permeability of the material being the same as that of the air-gap, this leads to a drastic reduction in coil inductance. This reduction leads to increase the skin depth of the material alloy leading a scattering in the eddy currents in a wide area path, so the resistance is reduced, then the current increase. Also, at this temperature the heated material radiation is increased leading to increase the dissipated energy. This explains the decrease in temperature rising rate at this degree during the process. The practical implementation of this system will approve the simulation.

\section{THE IMPLEMENTATION}

To approve the simulation results, a prototype of the required induction furnace implemented by using a single-phase, selftuned power supply already exist in the lab suitable to feed the designed coil. The designed coil is connected to a tank capacitor in order to achieve a resonant frequency of $78 \mathrm{kHz}$. Fig. 19 show the laboratory implemented system [13].

The gear under study is located inside the induction coil as shown in Fig. 20 which represents the increase in the gear temperature during the experiment 


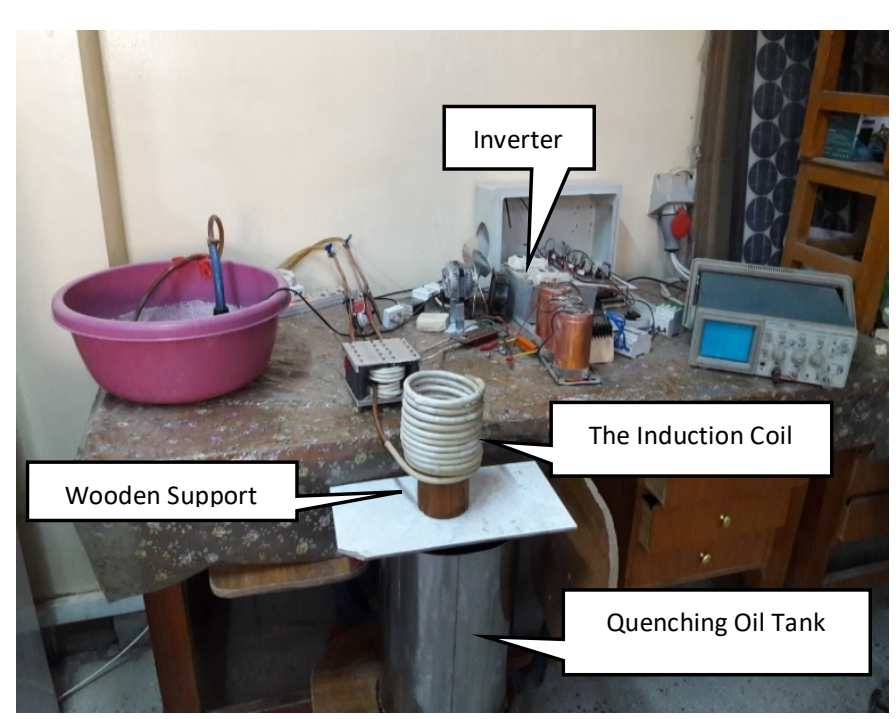

FIGURE 19. The experimental setup.

The practical steady state resonance frequency is $65.5 \mathrm{kHz}$, and the coil current is $180 \mathrm{~A}$, which means a current density of $9.531 \mathrm{MA} / \mathrm{m}^{2}$. When these values are fed to the simulation algorithm, the following results as shown if Fig. 20and Fig. 21 are obtained. The practical results show a good agreement with that of the simulation.

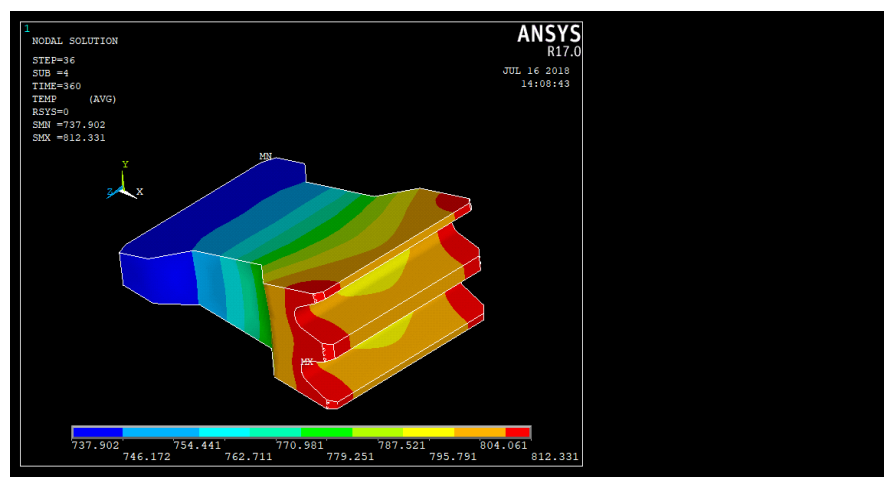

FIGURE 20. The temperature distribution on the gear at 360 s of the process

From Fig. 22 it is clear that the temperature is concentrated at the periphery of the gear at the region required to be hardened. The quenching started immediately after the heating process end by immerging the gear in the oil reservoir as shown in Fig. 19. This process leads to transfer the phase of the crystal lattice of the carbon steel to a Martensite type. This phase is the hardest one to protect the teeth from corrosion and wear.

The processed gear is subjected to a hardness test using a hardness test device. The test results are plotted as a function of gear radius as shown in Fig. 23. The hardness of the teeth region is from (490 to 520) Vickers which means that the Martensite concentration in this region is from $80 \%$ to $90 \%$ as shown in Fig. 24, which show the standard curves of the percentage content of the Martensite in the carbon steel due to their hardness level.

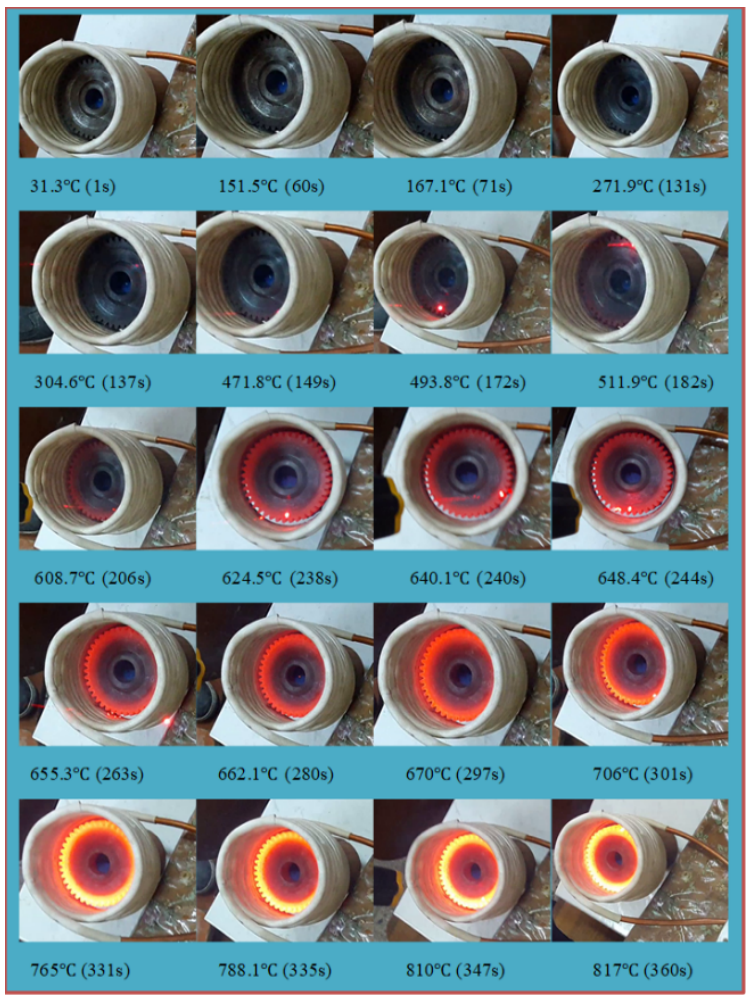

FIGURE 21. The temperature profile of the 5 nodes during the process of 300 s

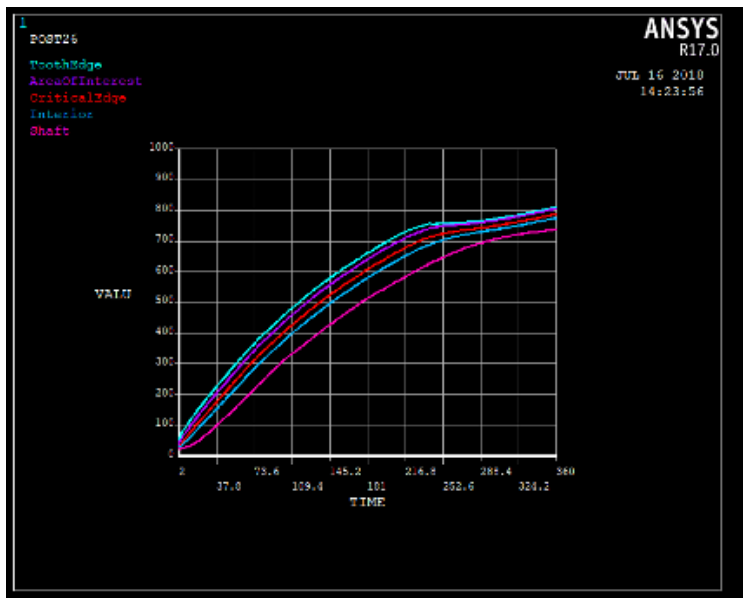

FIGURE 22. The steps of heating during 360s

\section{DISCUSSION}

It obvious that the practical parameters of the implemented system are not similar to those of the simulation due to the following: The connection resistances and that of the parallel capacitor affecting the resonant frequency. Also, this will affect on the quality factor of the tank circuit. This leads to reduce the coil current, so the processing time increased from $245 \mathrm{~s}$ to $360 \mathrm{~s}$. 


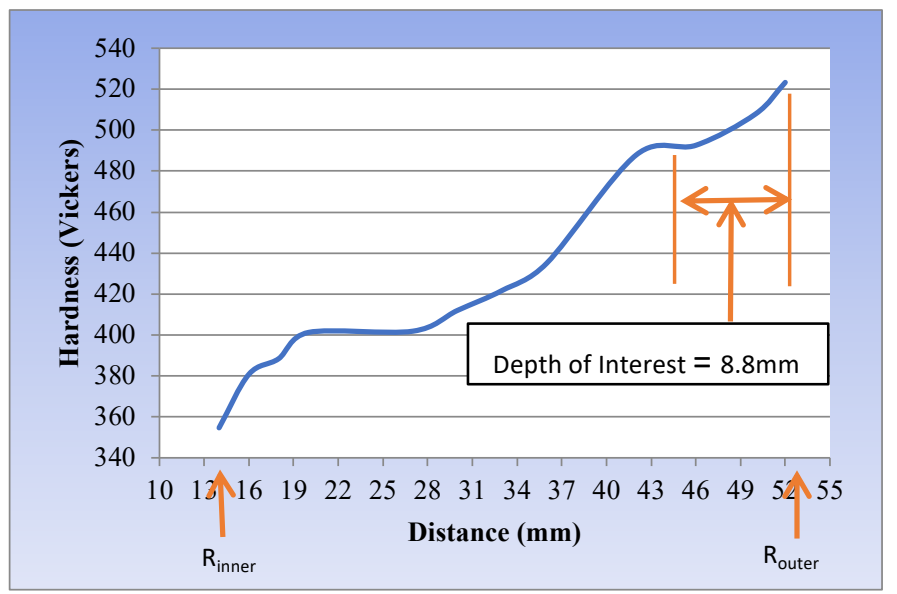

FIGURE 23. The hardness test results

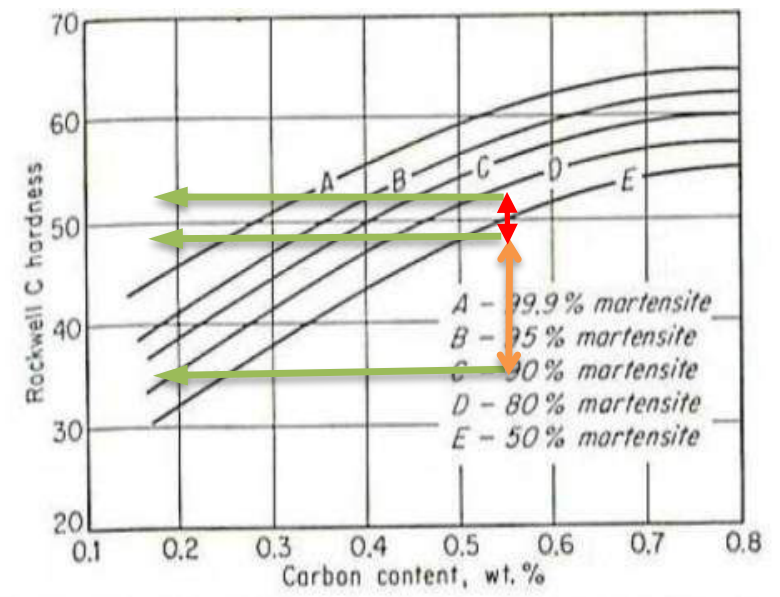

As-quenched hardness of steel as a function of carbon FIGURE 24. The percentage content of the Martensite

a) The effect of the temperature rise on the permeability of the carbon steel leads to change the value of the coil inductance and to change in the depth of the flux inside the gear.

b) At curie temperature a drastic increase in the coil current value as shown in Fig. 25. From this figure it is clear that this change occurs at the time between 290s and $310 \mathrm{~s}$. At this time Fig. 22 show that the Curie temperature reached. Then in spite of the increase in steel resistivity with temperature but the coil current increased due to the truth that the depth of the eddy current increases which means an increase in the crosssectional area of this flow leading to increase the current.

c) At curie temperature the resonance frequency of the tank circuit is changed also as shown in Fig. 26 due to change in steel permeability, and hence its self-inductance. Since the tank capacitor fixed, then the resonance frequency $\left(f_{s}\right)$ increased due to the approximate relation:

$$
f_{s}=\frac{1}{2 \pi \sqrt{L C}}
$$

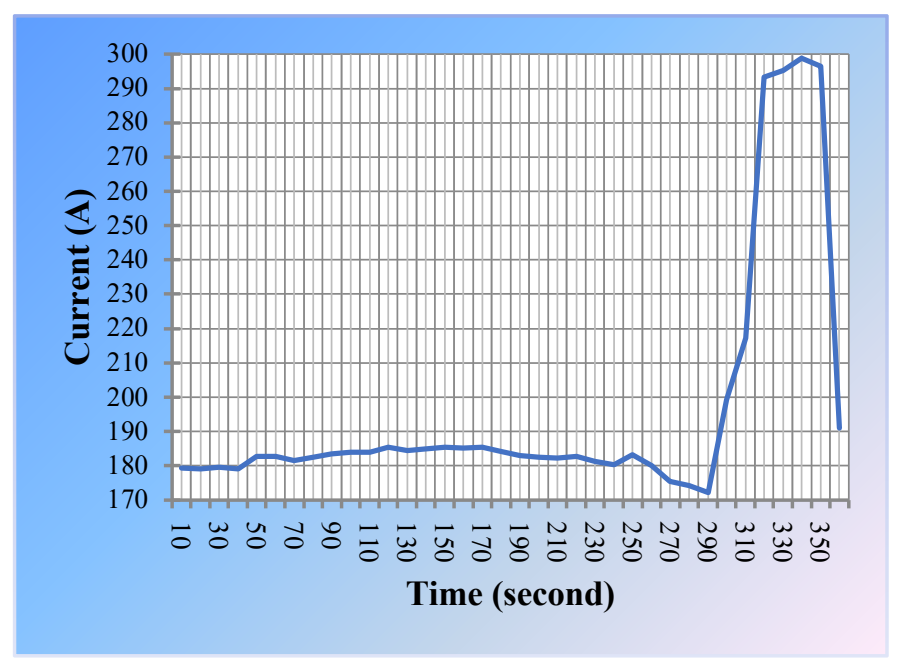

FIGURE 25. The coil current during the heating process

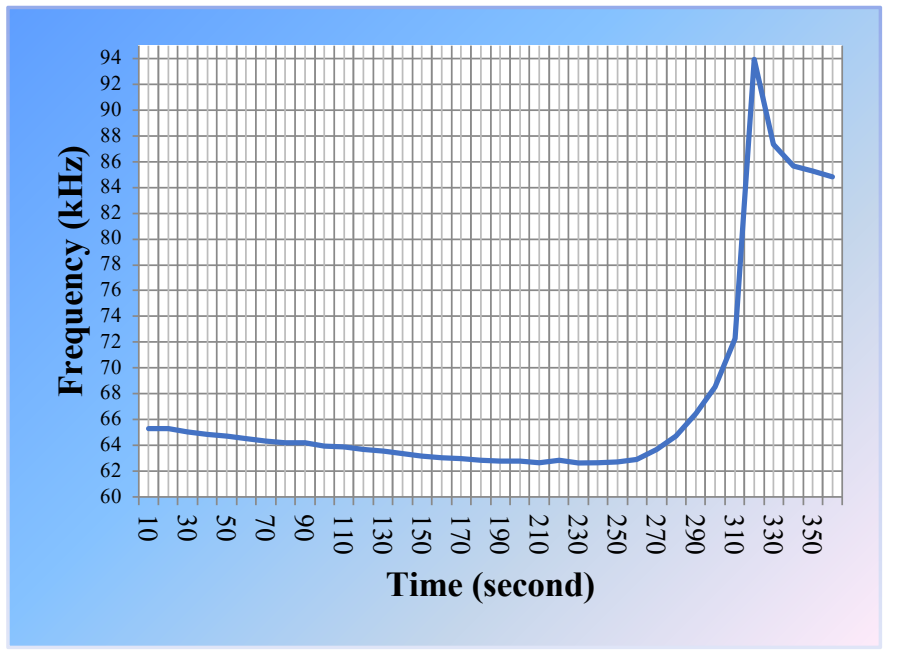

FIGURE 26. The change in coil current frequency the during heating process

d) The hardening process seems to be acceptable and the simulation results are very close to that obtained practically. This emphasize that for each specimen there are certain parameters and it has to be simulated due to the above explained procedure, and there is no common design equation for such coil.

\section{REFERENCES}

1. Haimbaugh, R.E., "Practical Induction Heat Treating", ASM International, Materials Park, Ohio, 2001.

2. Raymond A. Higgins, "Engineering Metallurgy", Sixth Edition, London, UK, 1993.

3. Daniel Fleisch, "A Student's Guide to Maxwell's Equations", the Edinburgh building, Cambridge, CB2 2RU, UK, 2008. 
4. Graham Woan, "The Cambridge Handbook of Physics Formulas", the Edinburgh building, Cambridge, CB2 2RU, UK, 2000.

5. George E. Totten, "Steel Heat Treatment Metallurgy and Technolgies", Second Edition, 2007.

6. Reza Abbaschian, Lara Abbaschian, Robert E. Reed-Hill, "Physical Metallurgy Principles", Fourth Edition, 200First Stamford Place, Suite 400 Stamford, CT 06902, USA, 2009.

7. A. Kulawik, A. Bokota, "Modelling of Quenching Process of Medium Carbon Steel", Institute of Computer and Information Sciences, University of Technology, Poland, 2009.

8. I. Magnabosco, P. Ferro, A. Tiziani, F. Bonollo, "Induction Heat Treatment of an ISO C45 steel Bar: Experimental and Numerical Analysis", Department of Management and Engineering, DTG University of Padova, Italy, 2005.

9. Habib Hammi, Noureddine Barka, Abderrazak El Ouafi "Effects of Induction Heating Process Parameters on Hardness Profile of 4340 Steel Bearing Shoulder Using 2D Axisymmetric Model", Mathematics, Computer, and Engineering Department, the University of Quebec at Rimouski, Rimouski, Quebec, Canada.

10. Ramón Bargallo, "Finite Elements for Electrical Engineering", EUETIBUPC, pp.195-219, 2006.

11. Isam Mahmood Abdulbaqi, "Analysis of Induction Furnace using FEM Electromagnetic-Thermal Coupled Approach", Ph.D. Thesis, Al-Rasheed College of Engineering and Science/ UOT, Baghdad, Iraq, January 2006.

12. Ramón Bargallo, "Finite Elements for Electrical Engineering", EUETIBUPC, pp.195-219, 2006.

13. Mohammad Hameed Khazaal, "Design, Simulation and Implementation of a High Frequency Power Source Feeding an Induction Furnace", Ph.D. Thesis, Basrah University, Iraq, 2016. 